\title{
Evaluation of symmetry behavior of surgically assisted rapid maxillary expansion with simulation-driven targeted bone weakening
}

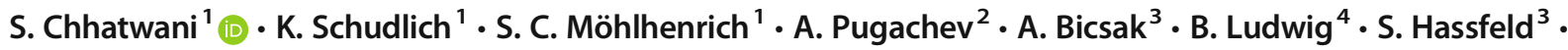 \\ G. Danesh ${ }^{1} \cdot$ L. Bonitz ${ }^{3}$
}

Received: 15 December 2020 / Accepted: 19 April 2021 / Published online: 5 May 2021

(C) The Author(s) 2021

\begin{abstract}
Objectives Surgically assisted rapid maxillary expansion (SARME) is a treatment modality to overcome maxillary constrictions. During the procedure of transverse expansion, unwanted asymmetries can occur. This retrospective study investigates the transverse expansion behavior of the maxilla utilizing a simulation-driven SARME with targeted bone weakening.

Materials and methods Cone beam computer tomographies of 21 patients before (T1) and 4 months after treatment (T2) with simulation-driven SARME combined with a transpalatal distractor (TPD) and targeted bone weakening were superimposed. The movements of the left, right, and frontal segments were evaluated at the modified WALA ridge, mid root level, and at the root tip of all upper teeth. Linear and angular measurements were performed to detect dentoalveolar changes.

Results Dentoalveolar changes were unavoidable, and buccal tipping of the premolars $\left(6.1^{\circ} \pm 5.0^{\circ}\right)$ was significant $(p<0.05)$. Transverse expansion in premolar region was higher $(6.13 \pm 4.63 \mathrm{~mm})$ than that in the molar region $(4.20 \pm 4.64 \mathrm{~mm})$. Expansion of left and right segments did not differ significantly $(p>0.05)$.

Conclusion Simulation-driven SARME with targeted bone weakening is effective to achieve symmetrical expansion in the transverse plane.

Clinical relevance Simulation-driven targeted bone weakening is a novel method for SARME to achieve symmetric expansion. Dental side effects cannot be prohibited.
\end{abstract}

Keywords Surgically assisted rapid maxillary expansion $\cdot \mathrm{CBCT} \cdot$ Asymmetry $\cdot$ 3D superimposition $\cdot$ Transpalatal distractor

\section{Introduction}

Maxillary constriction is a malocclusion with a prevalence of 8 to $10 \%$, which can be observed in adolescents and adults [1, 2]. Clinically, it is not only manifested in narrowed nasal

S. Chhatwani

sachin.chhatwani@uni-wh.de

1 Department of Orthodontics, Faculty of Health, University of Witten/ Herdecke, Alfred-Herrhausen-Str. 45, 58455 Witten, Germany

2 CADFEM Medical GmbH, Marktplatz 2, 85567 Grafing, Germany

3 Department of Cranial and Maxillofacial Surgery, Faculty of Health, University of Witten/Herdecke, Klinikum Nord, Münsterstr. 240, 44145 Dortmund, Germany

4 Private orthodontic clinic, Am Bahnhof 54, 56841 Traben-Trarbach, Germany cavities, arch length discrepancies, and anterior crowding but is usually also associated with a posterior crossbite occurring unilaterally or bilaterally $[3,4]$.

Studies have shown that the posterior crossbite is one of the most common dental malocclusions with a prevalence of 8 to $22 \%[5]$.

Once diagnosed, crossbites, whether dental or skeletal, should be treated, as they do not only lead to aesthetic problems but also influence function of the temporomandibular joint in the sense of incorrect loading and can lead to negative effects on body posture [6].

The main goal of treatment of skeletal crossbites caused by maxillary constrictions is to achieve a transverse skeletal expansion of the maxilla with the least possible dental influence, in order to achieve harmony of the lower and upper dental arches and to eliminate the discrepancies.

In order to achieve this treatment goal, Haas presented a tooth- and tissue-borne appliance consisting of molar bands 
that physically grasp the teeth assisted by two plastic bases that are connected medially by a screw [7].

This device was optimized by Biedermann in 1968, with an all wire frame and a jackscrew, known as the tooth-borne Hyrax expander [8].

Dentally anchored appliances are often accompanied by undesirable periodontal and orthodontic side effects, such as buccal tilting of teeth, root resorptions, cortical fenestration, and orthodontic relapses $[9,10]$. Mommaerts described the transpalatal distractor (TPD) in 1999, which consists of two telescopic cylinders and is anchored solely to the bone, thus ensuring skeletal force transmission. Anchoring and force transmission directly to the bone also allows not only for greater but also extremely efficient palatal expansion [10, 11]. For the sake of completeness, it should be mentioned that Hybrid Hyrax appliances, which are both skeletally and dentally anchored, can also be used for palatal expansion [12].

The midpalatal suture is subject to a relatively long process of ossification and is not yet ossified in childhood. In adults, on the other hand, it has numerous interlocked bone bridges, which are so heavy that separation of the two halves of the upper jaw is only possible with fracturing this interdigitation [13].

Opinions differ regarding age and the need of surgical assistance for this procedure. Epker and Wolford recommend a surgically assisted rapid maxillary expansion (SARME) after reaching the age of 16 [14]. Timms and Vero, on the other hand, claim that the maximum age for a conventional SARME should be 25 years [15].

Alpern and Yurosko also differed in their study by gender and concluded that SARME is indicated for men at over 25 years of age and for women at over 20 years of age [16].

A classification for midpalatal suture maturation utilizing cone beam computer tomography (CBCT) has been described by Angelieri et al. and shows that complete fusion of the midpalatal suture can already occur in females aged between 14 and 17 years [17]. In cases of completed mineralization with closure of the midpalatal suture, the use of SARME is advocated [18].

An increasing weakening of the bony pillars seems to affect the expansion behavior of the maxilla [19]. Especially, the zygomaticomaxillary junction plays a major role in resistance to expansion, and therefore, a corticotomy is performed from the piriform aperture to the pterygomaxillary junction. Some surgeons release the midpalatal suture to improve mobility, and also, a pterygoid disjunction seems to affect the pattern of maxillary expansion [20,21]. But its release is not preferred by all surgeons, [18] and its effect in context of orthodontic treatment is less [22].

Postoperative examination of the maxilla or biomechanical anatomic models show that expansion of the maxilla after SARME is often asymmetrical [23, 24]. Elkenawy et al. show asymmetric expansions in more than $50 \%$ of their sample group [25]. These asymmetries can also occur in oblique direction [26]. It has been reported that in cases of asymmetric expansion, an additional corrective surgery can be necessary [27]. A possible explanation besides other factors leading to these asymmetries could be differential bone density at the sutures and their surrounding structures [25].

In order to counteract these asymmetries, a simulationdriven surgical therapy with targeted bone weakening was performed for SARME. This study with its retrospective character investigates the transverse expansion behavior of the maxilla with this technique.

\section{Material and methods}

Data of all patients of the Department of Cranial and Maxillofacial Surgery, in Dortmund, who underwent a SARME in the period from May 2006 to June 2017 as part of an interdisciplinary orthodontic-surgical treatment, were examined for symmetry regarding the expansion procedure.

Inclusion criteria for this retrospective cohort study without control group were the availability of CTs or CBCTs before and after SARME and the presence of a maxillary transverse deficiency which was to be solved by surgically assisted rapid maxillary expansion utilizing a bone-borne transpalatal distractor (RPE, Gebrüder Martin GmbH \& Co. KG, Tuttlingen, Germany). All cases had to be operated by the same workflow with simulation-driven 3D planning and guide construction.

Patients with tooth extraction, tooth osteotomy, tumors, syndromal diseases, traumatic injuries, and severe craniofacial anomalies were excluded from the study. Patients with toothborne appliances or with CBCTs showing artifacts which prohibited the analysis were not eligible for this study. A total of 75 patients from 96 patients screened did not fulfill the inclusion criteria.

Total sample size consisted of 21 patients. The study group consisted of female and male patients. Data of patients were anonymized after collection.

Ethics approval for this study was given by the ethics committee of the University of Witten/Herdecke, Germany (application number 03/2019).

\section{Finite element simulation}

With the help of individual CT- or CBCT-based DICOM data, both the spatial configuration and the thickness of the remaining bone were analyzed and transferred into the simulation software to perform the preoperative "virtual osteotomy."

Three-dimensional finite element analysis (FEA) was used to examine deformation and stress-strain response of the anatomical model of the skull under the applied osteotomies and the distractor load before the surgery. The skull was segmented with MIS software (Mimics Innovation suite V20.0, 
Materialise NV, Leuven, Belgium) which allows analysis of individual differences of bone thickness (Fig. 1).

For finite element analysis, ANSYS Mechanical APDL 19.2 (ANSYS, Inc., Canonsburg, PA, USA) was used. The STL model of the individual skull with a specific osteotomy configuration was imported into ICEM CFD (ANSYS, Inc., Canonsburg, PA, USA) for meshing. Tetrahedral unstructured grids were generated in ANSYS ICEM CFD 19.2 based on the STL geometry of the skull.

A partially or complete opening of the lateral sinus wall and disconnection of the midpalatal suture, as advised by Lines, could be performed individually in the software environment (Fig. 2). Mesh refinement and mesh smoothing were generated to ensure a high finite element quality. An input file with the FE mesh was exported for the solver. The tetrahedral mesh file was imported into the ANSYS Mechanical APDL software application. With the programming language APDL (ANSYS Parametric Design Language), the definition of material properties and boundary conditions was performed. For the bone material, Poison's ratio of 0.3 and a modulus of elasticity of $15000 \mathrm{MPa}$ are defined. The transversal distraction of both palatal halves was simulated by applying a force of $150 \mathrm{~N}$ at the endpoints of the distractor which were individually adjusted.

The whole workflow with the meshing of bone geometry, the finite element model generation, and the simulation was performed automatically (Fig. 3).

The strain and stress plots and the deformation were exported for visual inspection. A sampling and statistical analysis was performed using optiSLang 7.2.0 (Dynardo GmbH, Weimar, Germany). The design variables were defined by the surgeon. To generate a large number of designs for the evaluation, the Latin hypercube sampling method (LHS) was applied. It describes a statistical method for generating a nearrandom sample of parameter values from a multidimensional

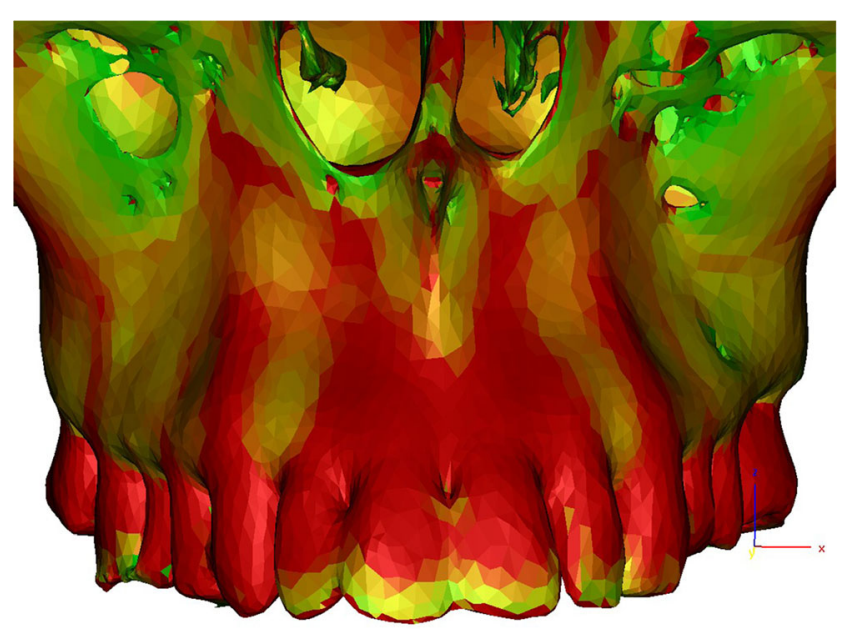

Fig. 1 Segmented maxilla with color-coded bone thickness (green, thin bone layer; red, thick bone layer)

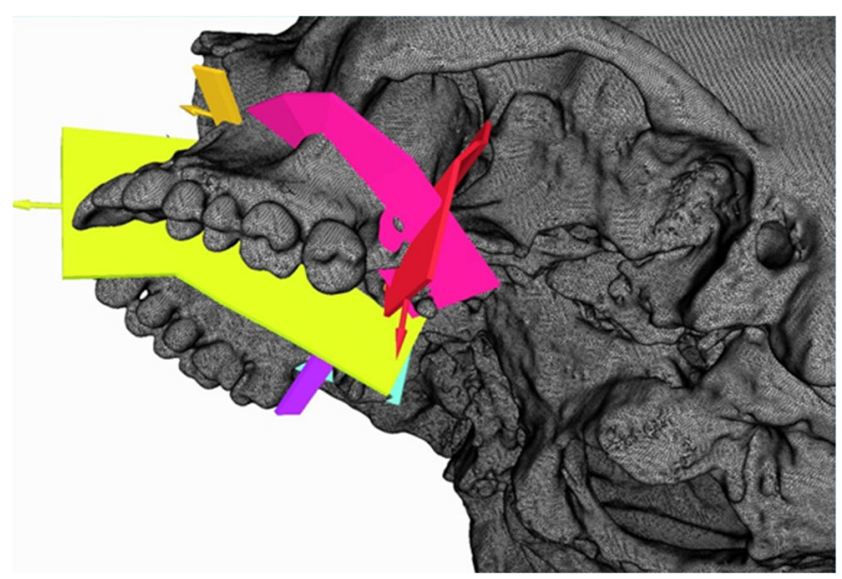

Fig. 2 Insertion of individual planes for osteotomy

distribution. Between the ANSYS software and the optiSLang software, an interface for transfer of values was implemented.

A symmetrical expansion of the maxilla is favored by a small difference in the stiffness of the maxillary bone of the left and right sides. This value is assumed to be the asymmetry criterion based on biomechanical principles. The smaller the difference, the more symmetrical expansion can be achieved.

For reliability and optimization of computational results, a minimum number of 100 iterations was performed. The resulting osteotomy configuration was critically evaluated by the surgeon.

The simulation results were then used to create an individual surgical guide (ANSYS SpaceClaim software ANSYS Inc., Canonsburg, USA) for the left and right sides via CAD/CAM technique and subsequently milled (Hermle C30U, Maschinenfabrik Berthold Hermle AG, Gosheim, Germany) from PEEK (polyetheretherketone) [28, 29] (Fig. 4).

\section{Surgical procedure}

All surgical procedures were carried out by the same surgeon.

The osteotomy was performed piezosurgically at the Le Fort I level. Based on Line's technique of osteotomy from 1975, this modified procedure leaves iatrogenic bone bridges in the area of the canines due to their pronounced root length [30]. After anesthesia, the incision of the mucosa was made paramarginally, vestibular from region 13 to 16 and region 23 to 26 , with tunnelation anteriorly and posteriorly. The submucosal and subperiosteal preparation in tunnel technique extends into the infraorbital region as well as via the zygomaticoalveolar crest to the retrotubar maxillary region and into the pterygopalatine fossa. The surgical guide for one side was then inserted (Fig. 5). Subesquent osteotomy of the vestibular wall of the maxillary sinus in accordance with the recesses of the respective surgical guide (right vs. left) was performed. The bone incisions through the maxillary bone were started laterally following the guide with a piezosurgery approach 
Fig. 3 Complex workflow for bone segmentation and statistical analysis

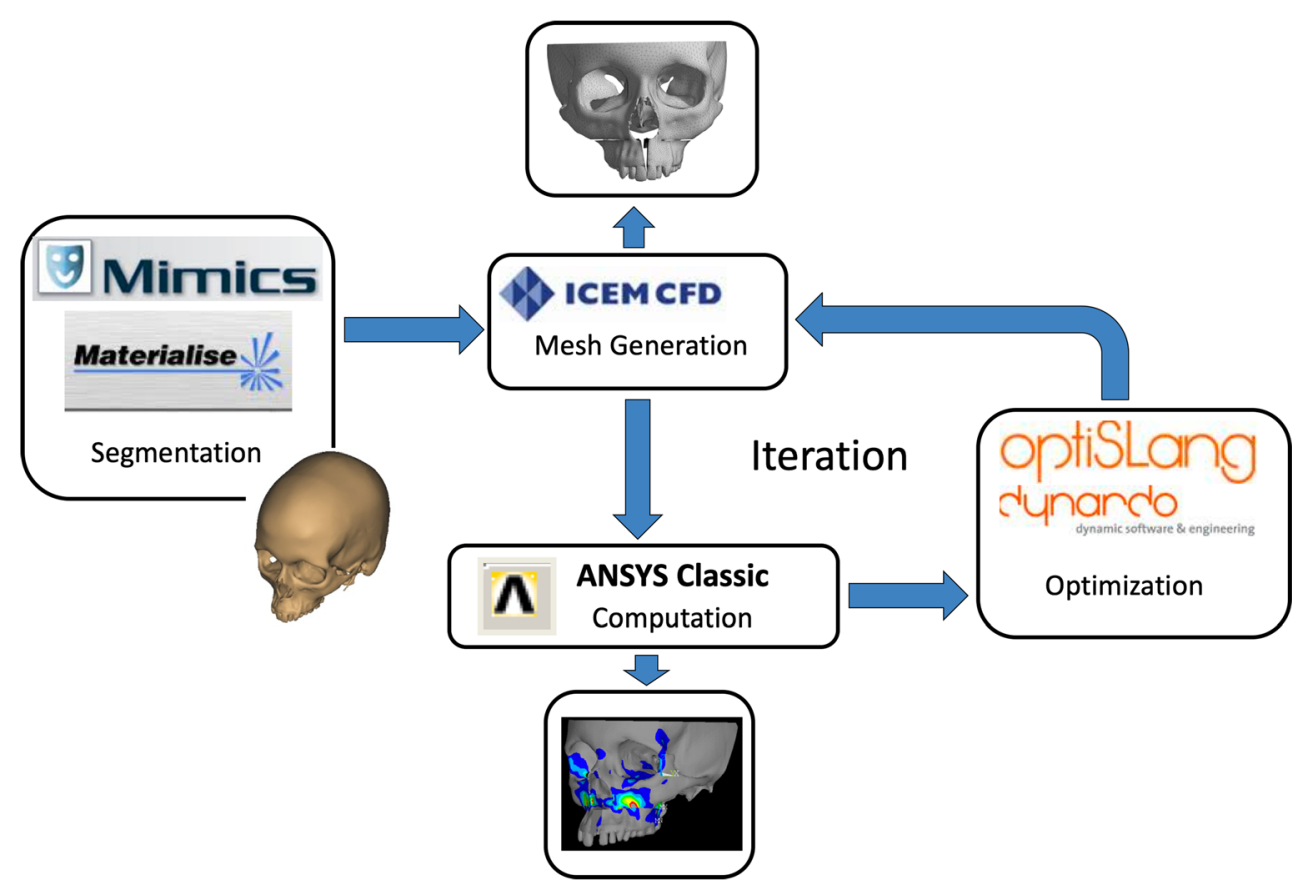

the patient by $0.5-1 \mathrm{~mm}$ until desired expansion was achieved.

\section{D Superimposition and measurements}

All CBCT scans were made with Sirona GALILEOS and GALILEOS plus (Dentsply Sirona, Bensheim, Germany).

The CBCTs were collected before (T1) and 4 months after (T2) the surgical procedure with a slice thickness of $0.3 \mathrm{~mm}$. The output data, a DICOM file, was converted into a reconstructed, virtual, three-dimensional model (STL file) with the software InVesalius 3.1 (CTI, Brazil), and an area of interest was selected, and the virtual object was then cropped in the

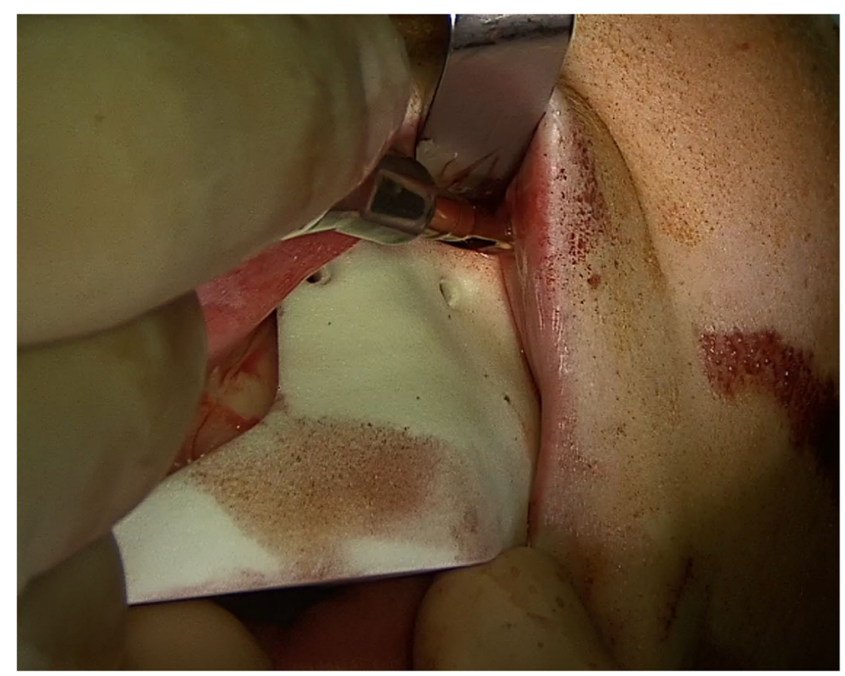

Fig. 5 Introperative insertion of the surgical guide 
same software. The STL data files for T1 and T2 for each patient were then transferred to the 3D inspection software GOM Inspect V7.5 (GOM GmbH, Braunschweig, Germany), which was used to superimpose the threedimensional models

After automatic pre-alignment, a local best fit was performed to superimpose $\mathrm{T} 1$ and $\mathrm{T} 2$ data by a defined bony area of the anterior cranial base. Anatomical landmarks were the greater wings of the sphenoid bone and the sella turcica.

In order to examine the symmetry obtained in the transversal plane during expansion by means of a targeted bone weakening, 3D surface distance comparisons were carried out at predefined points at level of the teeth from 16 to 26 .

These points include a modified WALA Ridge, the root tip, and a point in the middle third of the root on a line connecting the modified WALA Ridge and root tip (Fig. 6).

The WALA Ridge is an anatomical feature coronal to the mucogingival junction but refers to soft tissue and to the mandible [31]. The modified WALA Ridge is defined in this study as the thickest hard tissue landmark in an area coronal of the assumed mucogingival junction of the maxilla.

In general, 36 points should be measured per patient if no teeth were missing.

Lengths and angles were also measured with RadiAnt DICOM Viewer (Medixant, Poznan, Poland).

At first, the midpalatal suture was identified, and a vertical line was drawn through it in the coronal plane so that this line could be used as reference. Subsequently, the distance of the palatal root tips of the upper molars (16 and 26) and the first bicuspids (14 and 24) was measured to this reference line (Fig. $7 \mathrm{a}$.). In addition, the angle between the palatal root tip of the same teeth and the occlusal plane was measured (Fig. 7b). Finally, the transverse width between the buccal cusp tips of 16 and 26 and 14 and 24 was measured (Fig. 7c).

All acquired data were entered in a spreadsheet (Excel 2019, Microsoft Corporation, Redmond, USA) and transferred into a statistics software MEDAS IT (C Grund, EDV Systems, Margetshoechheim, Germany). Descriptive statistics and Wilcoxon pairwise comparison for dependent samples were performed. Additionally, a cluster analysis according to Ward [32] and pairwise comparison for independent samples in the form of Mann-Whitney $U$-tests were performed to analyze differences by type of cluster. For evaluation of statistical differences in left/right asymmetry of the clusters, twofactorial analysis of variance with repeated measurements on one factor was used.

Even though all patients were evaluated in general, some had to be excluded from certain measurements due to insufficient image quality of the CBCTs or due to absence of teeth.

\section{Results}

\section{Transverse width changes at buccal cusps}

The distance of the width of the buccal cusp tips between 14 and 24 differs significantly from $\mathrm{T} 1$ to $\mathrm{T} 2(p<0.001)$. The mean difference was $6.13 \mathrm{~mm} \pm 4.6 \mathrm{~mm}$.

Also, the transverse width in the area of the first molars was significantly different when comparing $\mathrm{T} 1$ and $\mathrm{T} 2(p<0.01)$ with a mean difference of $4.2 \mathrm{~mm} \pm 4.64 \mathrm{~mm}$ (Table 1 ).

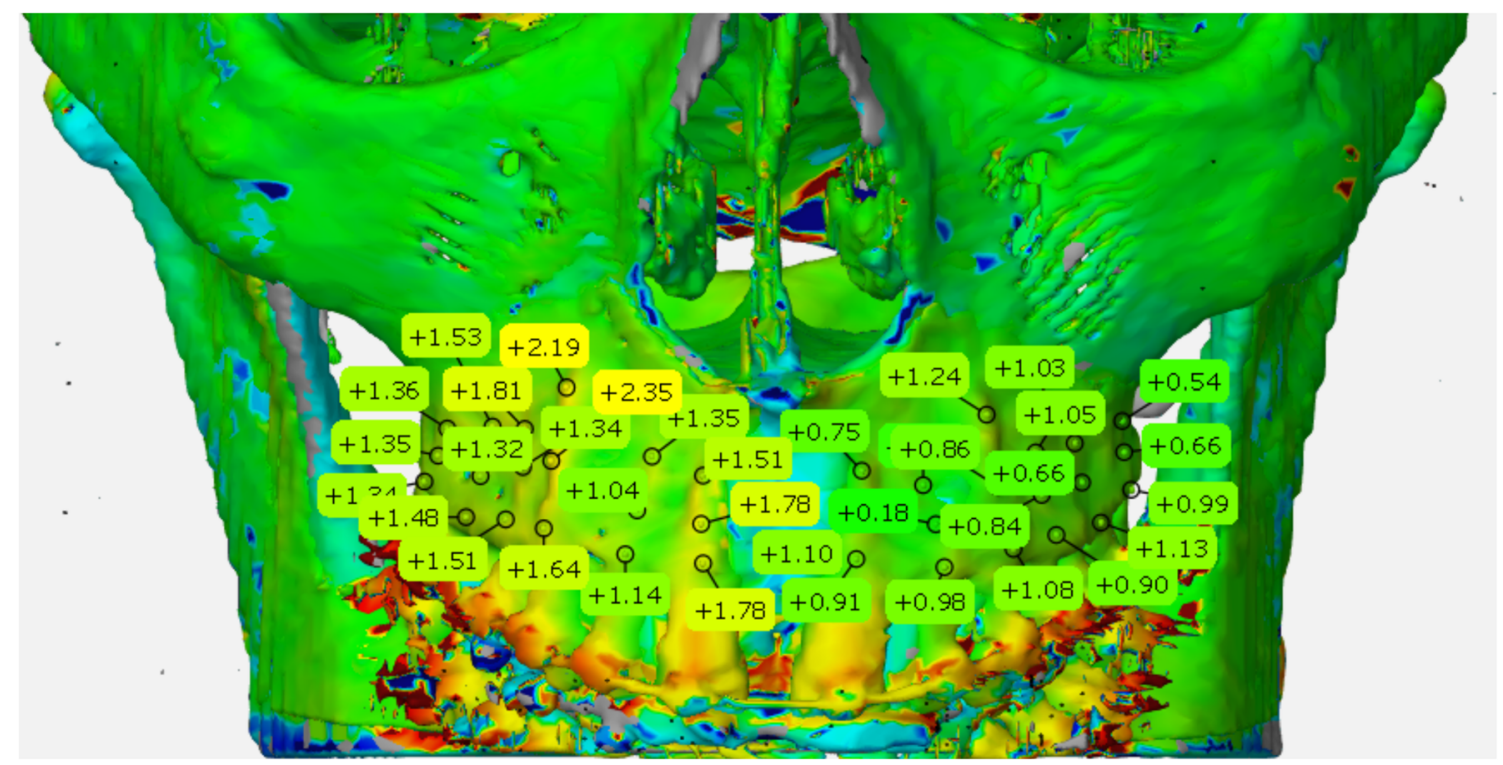

Fig. 6 Surface distance comparison of superimposed CBCTs from T1 and T2 with defined maxillary landmarks 

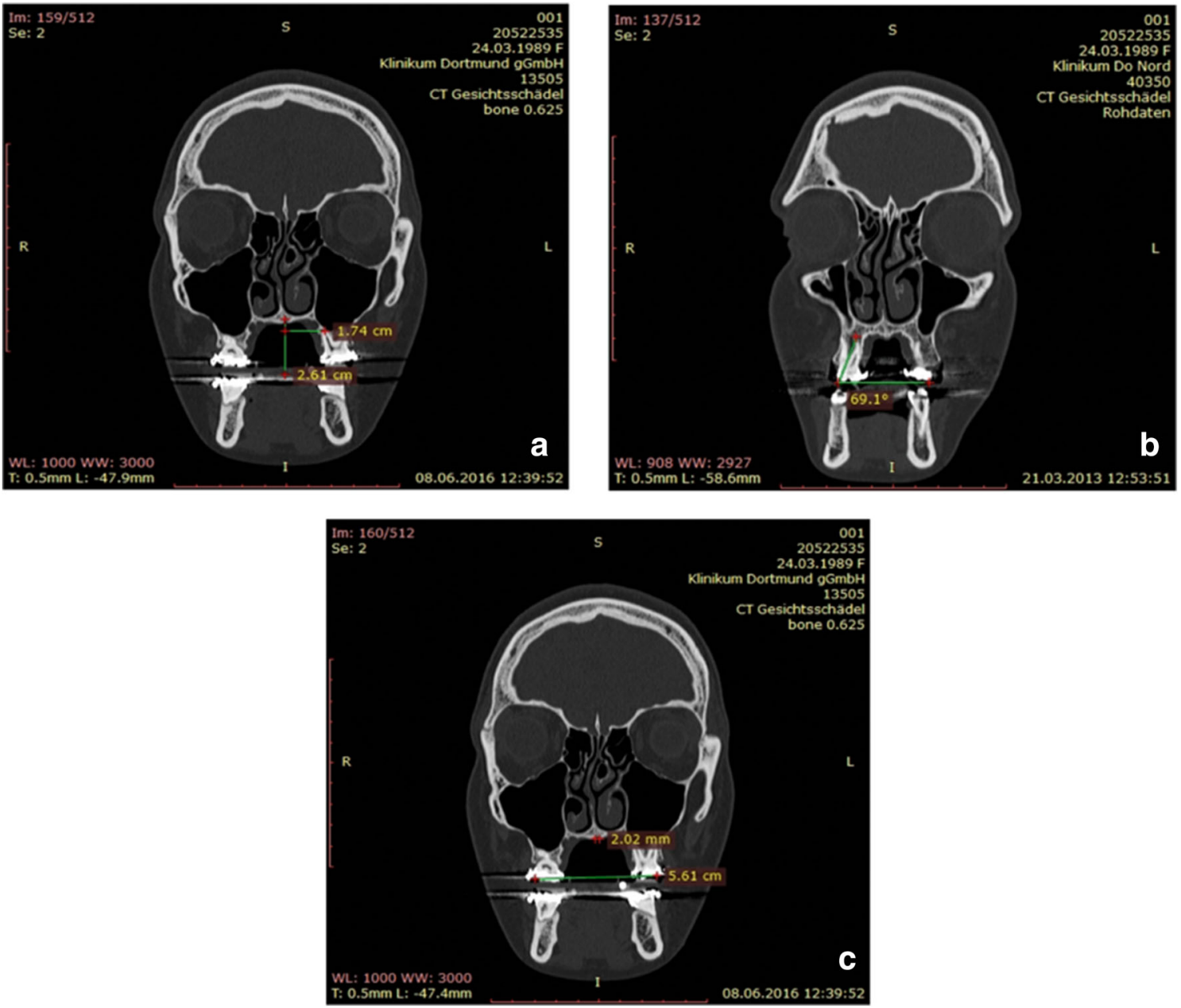

Fig. 7 a Measurement from a reference line at the midpalatal suture to the palatal root tip of the upper molar. b Angular measurement of the upper molar to the occlusal plane. $\mathbf{c}$ Transverse width measurement from buccal cusp to buccal cusp of the upper molars

\section{Distance of root apex to midpalatal suture}

The distances of the apices of the upper first premolars and upper molars to the midpalatal suture show significant changes from $\mathrm{T} 1$ to $\mathrm{T} 2(p<0.05)$.

A mean increase in distance of the apex of 14 to the midpalate suture by $0.97 \mathrm{~mm} \pm 1.69 \mathrm{~mm}$ was to be seen whereby the distance of the root of 24 showed an increase of $1.96 \mathrm{~mm} \pm 1.55 \mathrm{~mm}$.
The distances of the apices of the first upper molars showed an increase of $1.38 \mathrm{~mm} \pm 1.41 \mathrm{~mm}$ on the right side and by $1.26 \mathrm{~mm} \pm 1.48 \mathrm{~mm}$ on the left side (Table 2).

Angular changes of teeth to the occlusal plane were measured at time $\mathrm{T} 1$ compared to time $\mathrm{T} 2$ for the upper first premolars and first molars. These results show significant differences changes in angular changes change at time from $\mathrm{T} 1$ to $\mathrm{T} 2$ at for all teeth $(p<0.05)$. Generally, the angles measured became more acute with the highest changes for tooth 14 (-
Table 1 Wilcoxon test for two dependent samples comparing transverse width at $\mathrm{T} 0$ and $\mathrm{T} 1$ ( $n$ sample size, $S D$ standard deviation)

\begin{tabular}{llllllll}
\hline \multicolumn{2}{l}{ Transverse width } & & & & \\
\hline Teeth & Time & $n$ & $\begin{array}{l}\text { Mean } \\
(\mathrm{mm})\end{array}$ & SD & $\begin{array}{l}\text { Mean of difference } \\
(\mathrm{mm})\end{array}$ & $\begin{array}{l}\text { SD of difference } \\
(\mathrm{mm})\end{array}$ & Wilcoxon $p$ \\
\hline $14-24$ & T1 & 20 & 39.6 & 4.9 & 6.13 & 4.63 & \\
$14-24$ & T2 & 20 & 45.7 & 2.7 & & 4.64 & $\mathbf{0 . 0 0 0 2 4 * * *}$ \\
$16-26$ & T1 & 19 & 50.9 & 5.3 & 4.2 & & $\mathbf{0 . 0 0 4 * *}$ \\
$16-26$ & T2 & 19 & 551 & 3.1 & & & \\
\hline
\end{tabular}

$*=p<0.05 ; * *=p<0.01 ; * * *=p<0.001$ 
Table 2 Transverse width changes at apices of teeth from T1 to T2 and Wilcoxon dependent pairwise comparison ( $n$ sample size, $S D$ standard deviation)

\begin{tabular}{|c|c|c|c|c|c|c|c|}
\hline \multicolumn{2}{|c|}{ Distance Tooth } & \multirow{2}{*}{$\begin{array}{l}n \\
20\end{array}$} & \multirow{2}{*}{$\begin{array}{l}\text { Mean }(\mathrm{mm}) \\
16.5\end{array}$} & \multirow{2}{*}{$\begin{array}{l}\text { SD } \\
2.9\end{array}$} & \multirow{2}{*}{$\begin{array}{l}\begin{array}{l}\text { Mean of difference } \\
(\mathrm{mm})\end{array} \\
0.97\end{array}$} & \multirow{2}{*}{$\begin{array}{l}\begin{array}{l}\text { SD of difference } \\
(\mathrm{mm})\end{array} \\
1.69\end{array}$} & \multirow[t]{2}{*}{ Wilcoxon $p$} \\
\hline 14 & $\mathrm{~T} 1$ & & & & & & \\
\hline & $\mathrm{T} 2$ & 20 & 17.4 & 2.4 & & & $0.026^{*}$ \\
\hline \multirow[t]{2}{*}{16} & $\mathrm{~T} 1$ & 19 & 18.4 & 3.5 & 1.38 & 1.41 & \\
\hline & $\mathrm{T} 2$ & 19 & 19.8 & 3.2 & & & $0.00072 * * *$ \\
\hline \multirow[t]{2}{*}{24} & $\mathrm{~T} 1$ & 20 & 16.2 & 2.5 & 1.96 & 1.55 & \\
\hline & $\mathrm{T} 2$ & 20 & 18.2 & 2.3 & & & $0.0001 * * *$ \\
\hline \multirow[t]{2}{*}{26} & $\mathrm{~T} 1$ & 20 & 19.0 & 3.9 & 1.26 & 1.48 & \\
\hline & $\mathrm{T} 2$ & 20 & 20.3 & 3.7 & & & $0.0034 * *$ \\
\hline
\end{tabular}

$*=p<0.05 ; * *=p<0.01 ; * * *=p<0.001$

$\left.6.11^{\circ} \pm 5.02^{\circ}\right)$ and lowest change in angular measurement for $16\left(-2.93^{\circ} \pm 4.58^{\circ}\right)($ Table 3$)$.

\section{Movement of segments}

The maxilla was divided into three segments, namely a right $(13,14,15,16)$, frontal $(12,11,21,22)$, and left $(23,24,25$, 26) segment. The median value of all surface measurement points for each of these three segments was determined.

Subsequently, mean values of the median values of each expanded segment were determined, resulting in a mean value of $0.18 \mathrm{~mm} \pm 1.37 \mathrm{~mm}$ for the frontal segment, $1.67 \mathrm{~mm} \pm$ $1.28 \mathrm{~mm}$ for the left segment, and $1.14 \mathrm{~mm} \pm 1.09 \mathrm{~mm}$ for the right segment.

The Wilcoxon test indicated statistically significant differences in amount of movement of the frontal segment compared to the left $(p<0.001)$ and the frontal segments compared to the right segment $(p<0.01)$. The left and right segments moved more than the frontal segment. Analyzing the cases globally shows a statistically insignificant difference in amount of movement between the left and right segments ( $p>0.05$ ) (Table 4). The movement of the frontal segment was evaluated for the sake of completeness.

\section{Cluster analysis}

A cluster analysis of all 36 position deviations was carried out to group the patients regarding similarities. Cluster 1 incorporates 15 patients that showed more movement of the segments than the other 6 patients which were grouped into cluster 2 .

To assess significant differences, the median values of the front, left, and right segments between the two clusters' $U$-test according to Mann and Whitney was applied.

The median value for movement of the frontal segment of cluster 1 was $1.03 \mathrm{~mm}(68 \%$ CI 1.64 to $-0.56 \mathrm{~mm})$ and differed significantly $(p<0.05)$ compared to $-0.71 \mathrm{~mm}(68 \%$ CI 0.25 to $-2.31 \mathrm{~mm}$ ) for cluster 2 .

For the movement of the left segment of cluster 1, a median value of $1.71 \mathrm{~mm}$ (68\% CI 3.38-1.18mm) was noted and for cluster 2 a value of $0.61 \mathrm{~mm}(68 \% \mathrm{CI} 1.02-0.16 \mathrm{~mm})$. The difference between the left segments was significant $(p<0.01)$. The comparison of the right segment of cluster 1 with a median value of $1.68 \mathrm{~mm}(68 \%$ CI $2.43-1.04 \mathrm{~mm})$ and $-0.23 \mathrm{~mm}$ (68\% CI 0.45 to $-0.72 \mathrm{~mm}$ ) showed significant differences $(p$ $\leq 0.001)$ (Table 5).

It is noticeable that although no significant differences were measured in the median comparison of the left and right
Table 3 Angular changes of the tooth axis to the occlusal plane in degrees ( $n$ sample size, $S D$ standard deviation)

\begin{tabular}{|c|c|c|c|c|c|c|c|}
\hline Tooth & Time & $n$ & Mean (degrees) ${ }^{\circ}$ & SD & $\begin{array}{l}\text { Mean of difference } \\
\text { (degrees) }^{\circ}\end{array}$ & 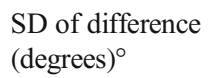 & $\begin{array}{l}\text { Wilcoxon } \\
p\end{array}$ \\
\hline \multirow[t]{2}{*}{14} & $\mathrm{~T} 1$ & 20 & 80.23 & 8.44 & -6.11 & 5.015 & \\
\hline & $\mathrm{T} 2$ & 20 & 74.12 & 7.05 & & & $0.0002 * * *$ \\
\hline \multirow[t]{2}{*}{16} & $\mathrm{~T} 1$ & 19 & 71.65 & 10.35 & -2.932 & 4.583 & \\
\hline & $\mathrm{T} 2$ & 19 & 68.72 & 9.63 & & & $0.019 *$ \\
\hline \multirow[t]{2}{*}{24} & $\mathrm{~T} 1$ & 20 & 79.43 & 8.24 & -3.145 & 6.788 & \\
\hline & $\mathrm{T} 2$ & 20 & 76.29 & 5.27 & & & $0.038^{*}$ \\
\hline \multirow[t]{2}{*}{26} & $\mathrm{~T} 1$ & 20 & 73.96 & 11.01 & -3.69 & 5.973 & \\
\hline & $\mathrm{T} 2$ & 20 & 70.27 & 11.69 & & & $0.013^{*}$ \\
\hline
\end{tabular}

$*=p<0.05 ; * *=p<0.01 ; * * *=p<0.001$ 
Table 4 Comparison of the segments utilizing the Wilcoxon test ( $n$ sample size, SD standard deviation)

\begin{tabular}{lllllll}
\hline Segment & $n$ & Mean $(\mathrm{mm})$ & SD & Mean of difference $(\mathrm{mm})$ & SD of difference $(\mathrm{mm})$ & Wilcoxon $p$ \\
\hline Frontal & 21 & 0.18 & 1.37 & -1.49 & 1.28 & $\mathbf{0 . 0 0 0 1 5 * * *}$ \\
Left & 21 & 1.67 & 1.28 & & 1.28 & \\
Frontal & 21 & 0.18 & 1.37 & -0.97 & & $\mathbf{0 . 0 0 3 5 * *}$ \\
Right & 21 & 1.14 & 1.09 & & 1.17 & $\mathbf{0 . 0 6 8}$ \\
Left & 21 & 1.67 & 1.28 & 0.53 & & \\
Right & 21 & 1.14 & 1.09 & & & \\
\hline
\end{tabular}

$*=p<0.05 ; * *=p<0.01 ; * * *=p<0.001$ segments (Table 4), a median comparison of the right segment shows significant differences between the two clusters (Table 5).

Furthermore, a two-factorial analysis of variance with repeated measurements on one factor was performed to compare expansion symmetry between left and right segments.

While the right and left segments did not differ significantly from each other in regard to their movement $(p=0.53)$, a very significant difference was observed between clusters 1 and $2(p=0.0013)$, showing that cluster 1 had a higher amount of movement in both segments than cluster 2. An additional comparison within each cluster regarding left and right symmetry showed no significant changes $(p=0.073)$.

Fig. 8 shows the median values of the skeletal landmarks assessed at each tooth respecting the cluster grouping. It is visible that cluster 1 experienced more expansion than cluster 2 and that the curves are nearly symmetrical for the left and right side (Fig. 8).

To evaluate for asymmetric expansion for each individual case, the median value of the left and the right segments for each patient can be used in a graphical representation. The straight line represents the line of equal values. It can be seen that three dots, each representing patients, or $14.3 \%$ of the patients are not within the surrounding of this line showing an asymmetric expansion with greater movement of the left segment (Fig. 9).

\section{Discussion}

Asymmetric expansions, where one half of the maxilla moves more than the other, have been described as a complication of
SARME procedures $[18,24]$. Since the bone structures of the midface are generally not symmetrical to each other, the transverse widening, after fixation of the bone-anchored distractor to the palate, is also not symmetrical. A side-dependent difference in the bone stiffness forces an asymmetrical distraction. In most cases of transversal expansion the asymmetry can be compensated by tooth movement. In the worst case, correction of this situation would mean patients have to undergo another surgical intervention [27].

This study investigates expansion behavior regarding symmetry after targeted bone weakening of the maxilla in surgically assisted rapid maxillary expansion.

Pre- and postsurgical CBCTs were superimposed at the anterior cranial base with a 3D measurement software GOM inspect (GOM GmbH, Braunschweig, Germany) in this study by means of a local best fit. This software has proven itself in other studies for superimposition purposes [33, 34].

Superimposition of CBCT models using the anterior cranial base as reference, like in this study, has shown to be accurate. This area is also not affected by the expansion of a SARME and provides accurate results [35].

The treatment method used in this study is based on that of Lines, which was published in 1975 [30]. Lines' treatment procedure is based on Le Fort I level with an osteotomy starting from the apertura piriformis and extending over the zygomatic columns to the maxillary tuberosity. He emphasizes that a further distal extension up to the pterygomaxillary fissure is not necessary, because this way damage to the pterygoid plexus and the descending palatal artery can be avoided.

Seeberger et al. concluded that a separation of the pterygomaxillary connection can be dispensed during the
Table 5 Median comparison between cluster 1 and cluster 2 with Mann-Whitney $U$ - test (n sample size, $S D$ standard deviation, $C I$ confidence interval)

\begin{tabular}{lllllllll}
\hline Segment & & $n$ & Mean $(\mathrm{mm})$ & $\mathrm{SD}$ & Median $(\mathrm{mm})$ & $68 \%$ CI & & $U$-test $p$ \\
\hline Frontal & Cluster 1 & 15 & 0.668 & 1.02 & 1.030 & 1.637 & -0.558 & \\
& Cluster 2 & 6 & -1.044 & 1.438 & -0.705 & 0.254 & -2.311 & $\mathbf{0 . 0 1 1 *}$ \\
\multirow{2}{*}{ Left } & Cluster 1 & 15 & 2.114 & 1.208 & 1.710 & 3.375 & 1.184 & \\
& Cluster 2 & 6 & 0.561 & 0.599 & 0.605 & 1.023 & 0.155 & $\mathbf{0 . 0 0 2 8 * *}$ \\
\multirow{2}{*}{ Right } & Cluster 1 & 15 & 1.689 & 0.658 & 1.680 & 2.431 & 1.044 & \\
& Cluster 2 & 6 & -0.218 & 0.67 & -0.230 & 0.451 & -0.722 & $\mathbf{0 . 0 0 0 1 5 * * *}$ \\
\hline
\end{tabular}

$*=p<0.05 ; * *=p<0.01 ; * * *=p<0.001$ 


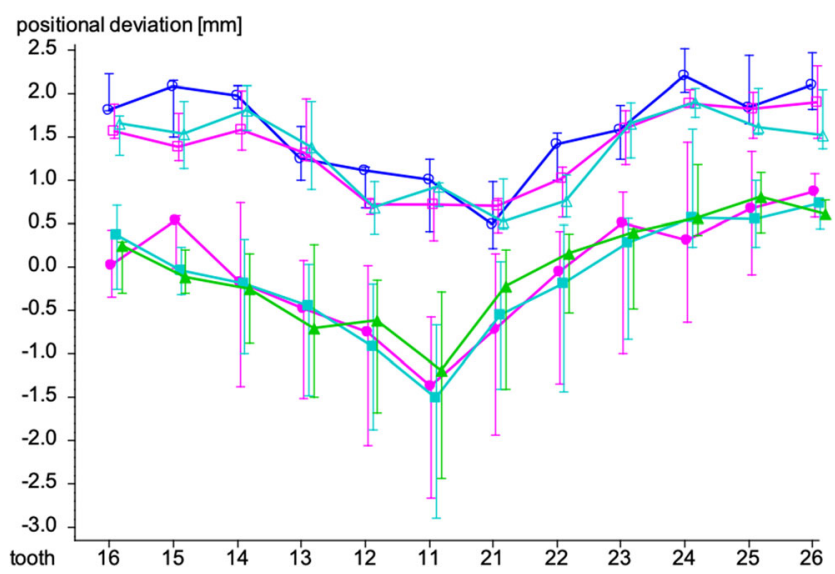

Fig. 8 Graphical representation of the median values with $68 \%$ CI of cluster $1(\mathrm{C} 1)$ and cluster $2(\mathrm{C} 2)$ for the positional deviation at level of modified WALA, middle third of root, and root tip for each tooth. $\bigcirc$, mod WALA $\mathrm{C} 1 ; \square$, mid root $\mathrm{C} 1 ; \triangle$, root apex $\mathrm{C} 1 ; \boldsymbol{\bullet}, \bmod$ WALA $\mathrm{C} 2$;, mid root $\mathrm{C} 2$;, root apex $\mathrm{C} 2$

surgical procedure. However, this leads to an anteriorly accentuated V-shaped expansion due to the posterior resistance zone, so that a separation of this structure was obligatory to allow symmetrical expansion [36]. In two cadaveric studies, Möhlhenrich et al. reported about similar effects of pterygoid disjunction in context of SARME [20,37].

Our findings confirm this $\mathrm{V}$-shaped expansion pattern as transverse width measured at the buccal cusps of the first upper premolars and molars shows greater expansion in the area of the premolars. The interpremolar width changed by $6.13 \pm 4.63 \mathrm{~mm}$ and the intermolar width by $4.2 \pm 4.64 \mathrm{~mm}$. Ramieri et al. show an interpremolar change of $6.86 \pm 1.5 \mathrm{~mm}$ and an intermolar width change of $5.39 \mathrm{~mm} \pm 2.5 \mathrm{~mm}$ which seems to be in concordance with our findings and of those published in a literature

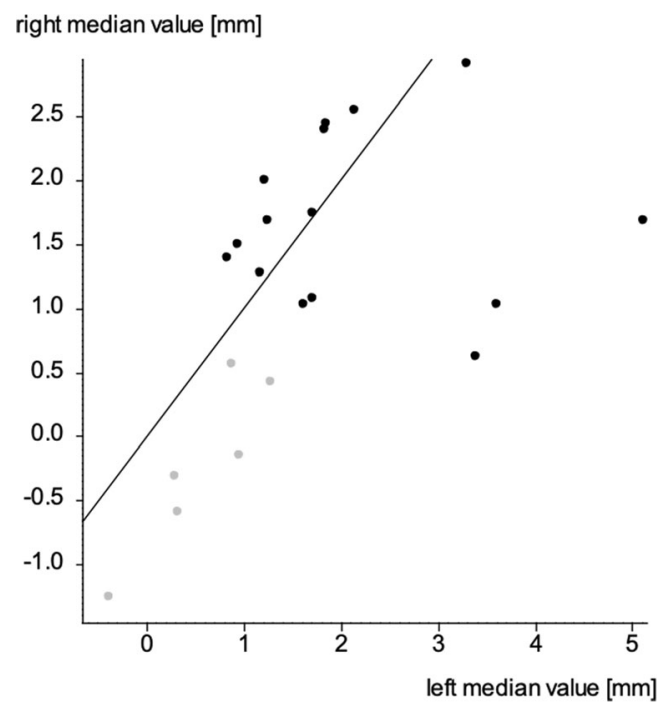

Fig. 9 Graphical display of symmetry of expansion, each dot representing a patient with the right and left median value. The line represents the line of equal values. $\bullet$, cluster 1 ;, , cluster 2 review by Koudstaal et al. [18, 26]. Negative values of movement as were seen in cluster 2 could be explained by a posterior inward rotation of the lateral segments by this V-shaped expansion pattern. These values could also be affected by positioning of the TPD in anteroposterior position as it has an effect on expansion pattern and on symmetry of expansion [38] and by vertical positioning of the device having an effect on segmental tipping [39].

Another study investigating the clinical effects of TPD demonstrates that the main effect of expansion is rather at level of the alveolar crest than in the maxillary base [40].

Measurements of distances of the root apices to a reference line at level of the midpalatal sutures in this study were less than the transverse width changes at the buccal cusps supporting the fact that expansion is less at the maxillary base compared to areas closer to the occlusal plane.

Regarding angular changes in this study first premolars and first molars showed a more acute angle of their long axis to the occlusal plane at $\mathrm{T} 1$ indicating buccal tipping of the teeth. Our findings are not in line with those of Pinto et al. as they even noticed a palatal tipping of the premolars by $8.3^{\circ} \pm 9.6^{\circ}$ [39].

A study investigating a tooth-borne SARME found at first premolar level $6.48^{\circ} \pm 2.29^{\circ}$ degrees of buccal tipping and at first molar $7.04^{\circ} \pm 4.58^{\circ}$ of buccal tipping [41]. By using a boneborne transpalatal distractor, we could achieve less buccal tipping, but it was still unavoidable. Similar results regarding buccal tipping by bone-borne devices have been described [24].

The amount of skeletal expansion achieved was less than the measurements of the transverse changes in interpremolar and intermolar width. Taking additionally into account that buccal tipping has occurred and that movement of the root apices was also minimal compared to more coronal movement, it has to be concluded that bone-borne devices have dental effects which are not to be neglected.

While investigating skeletal effects, the skeletal landmarks have to be chosen for 3D surface distance measurements. The defined landmarks were similar to another study investigating the expansion behavior of the maxilla, but instead of points, they used rectangular areas of bone for surface comparison [23].

Analyzing the movement of the skeletal segments with the Wilcoxon test globally for all patients revealed no significant difference in expansion of the left and right segment indicating a symmetrical expansion could be achieved. During the surgical procedure, iatrogenic bone bridges are left in the lateral sinus wall which have been varied by an iterative mathematical algorithm in order to achieve a symmetric expansion. This idea contradicts the concept of Kober stating that a more symmetric osteotomy leads to a more symmetrical expansion [42].

Cluster analysis revealed that in 15 patients of our study, there was a significantly higher effect in all three segments to be seen by transverse expansion to be seen than in the other 6 patients (Fig. 9). 
A possible reason for this could be the same rationale as described for asymmetric expansion like occlusal factors [24], resistance of tissues [23], or maybe the iatrogenic bridges at osteotomy enhancing higher resistance of hard tissue.

Two-factorial analysis of variance supports the fact that the left and right segments have expanded symmetrically for both clusters even if one cluster had a minor movement of the segments compared to the other.

Analysis of left/right asymmetry within the cluster showed no significant difference indicating symmetric expansion of the left and right segments $(p=0.073)$. The low $p$ value suggests looking at the cases individually and might indicate that the amount of distraction might play a role in order to aid symmetry.

It was found that 3 patients showed an asymmetric expansion, which is $14.3 \%$ of the sample size. An asymmetric skeletal expansion more than $3 \mathrm{~mm}$ is considered as clinically relevant, and another study has shown that this occurred in 55\% the patients evaluated [23]. Other studies have shown a significant asymmetric expansion in only $13.8 \%$ of the patients [42]. It should be taken into account that asymmetric transverse expansion can also be the result of an oblique placement of the transpalatal distractor [26]. An insertion with insertion guides may seem favorable.

From our observations, it can be concluded that there was a retraction of the anterior maxillary region. A similar finding was also made by Nada et al. who additionally reported on possible retroclination of the upper incisors [11].

This is a retrospective study without a predefined sample size or control group and is only of explorative character. The results of retrospective studies are to be interpreted with caution due to the limitations and as risk of bias can not be ruled out. Additional limitations of our study were that asymmetries were only considered in transverse plane and not in any other direction. This study did not take into account relapse movements. A surgical protocol was not predefined, but due to computational workflow with surgical guides, it was similar for all patients. A sample size calculation was not performed but relates to other studies analyzing expansion behavior [23].

Despite these restrictions, this study investigates a novel technique and could be of help for further research regarding development, validation, and provision of evidence for new $\mathrm{CAD} /$ CAM techniques in surgical interventions like SARME with targeted bone weakening.

\section{Conclusion}

CAD/CAM/CAE-aided SARME with targeted bone weakening can achieve symmetrical skeletal expansion of the left and right maxillary segments.

Using bone-borne distractors and computational simulation for surgical maxillary expansion does not prohibit dental effects in transverse expansion.
Funding Open Access funding enabled and organized by Projekt DEAL.

\section{Declarations}

Conflict of interest Alexander Pugachev is an employee of CADFEM Medical $\mathrm{GmbH}$, Grafing, Munich, and was involved in the development of the algorithm for simulation-driven SARME.

There is no conflict of interest for all other authors.

Open Access This article is licensed under a Creative Commons Attribution 4.0 International License, which permits use, sharing, adaptation, distribution and reproduction in any medium or format, as long as you give appropriate credit to the original author(s) and the source, provide a link to the Creative Commons licence, and indicate if changes were made. The images or other third party material in this article are included in the article's Creative Commons licence, unless indicated otherwise in a credit line to the material. If material is not included in the article's Creative Commons licence and your intended use is not permitted by statutory regulation or exceeds the permitted use, you will need to obtain permission directly from the copyright holder. To view a copy of this licence, visit http://creativecommons.org/licenses/by/4.0/.

\section{References}

1. Tausche E, Luck O, Harzer W (2004) Prevalence of malocclusions in the early mixed dentition and orthodontic treatment need. Eur J Orthod 26(3):237-244. https://doi.org/10.1093/ejo/26.3.237

2. Thilander B, Myrberg N (1973) The prevalence of malocclusion in Swedish schoolchildren. Scand J Dent Res 81(1):12-21. https://doi. org/10.1111/j.1600-0722.1973.tb01489.x

3. Lagravere MO, Carey J, Heo G, Toogood RW, Major PW (2010) Transverse, vertical, and anteroposterior changes from boneanchored maxillary expansion vs traditional rapid maxillary expansion: a randomized clinical trial. Am J Orthod Dentofacial Orthop 137(3):304 e301-304 e312; discussion 304-305. https://doi.org/10. 1016/j.ajodo.2009.09.016

4. Zandi M, Miresmaeili A, Heidari A (2014) Short-term skeletal and dental changes following bone-borne versus tooth-borne surgically assisted rapid maxillary expansion: a randomized clinical trial study. J Craniomaxillofac Surg 42(7):1190-1195. https://doi.org/ 10.1016/j.jcms.2014.02.007

5. Petren S, Bondemark L, Soderfeldt B (2003) A systematic review concerning early orthodontic treatment of unilateral posterior crossbite. Angle Orthod 73(5):588-596. https://doi.org/10.1043/ 0003-3219(2003)073<0588:ASRCEO>2.0.CO;2

6. Sidlauskiene M, Smailiene D, Lopatiene K, Cekanauskas E, Pribuisiene R, Sidlauskas M (2015) Relationships between malocclusion, body posture, and nasopharyngeal pathology in preorthodontic children. Med Sci Monit 21:1765-1773. https://doi. org/10.12659/MSM.893395

7. Haas AJ (1965) The treatment of maxillary deficiency by opening the midpalatal suture. Angle Orthod 35:200-217. https://doi.org/10. 1043/0003-3219(1965)035<0200:TTOMDB >2.0.CO;2

8. Shetty SK, Roginth Vigneshwaran A, Kumar M, Madhur V (2017) Expand the constricted-review article

9. Landes CA, Laudemann K, Schubel F, Petruchin O, Mack M, Kopp S, Sader RA (2009) Comparison of tooth- and bone-borne devices in surgically assisted rapid maxillary expansion by threedimensional computed tomography monitoring: transverse dental and skeletal maxillary expansion, segmental inclination, dental tipping, and vestibular bone resorption. J Craniofac Surg 20(4):11321141. https://doi.org/10.1097/scs.0b013e3181abb430 
10. Mommaerts MY (1999) Transpalatal distraction as a method of maxillary expansion. Br J Oral Maxillofac Surg 37(4):268-272. https://doi.org/10.1054/bjom.1999.0127

11. Nada RM, Fudalej PS, Maal TJ, Berge SJ, Mostafa YA, KuijpersJagtman AM (2012) Three-dimensional prospective evaluation of tooth-borne and bone-borne surgically assisted rapid maxillary expansion. J Craniomaxillofac Surg 40(8):757-762. https://doi.org/ 10.1016/j.jcms.2012.01.026

12. Wilmes B, Nienkemper M, Drescher D (2010) Application and effectiveness of a mini-implant- and tooth-borne rapid palatal expansion device: the hybrid hyrax. World J Orthod 11(4):323-330

13. Melsen B (1975) Palatal growth studied on human autopsy material. A histologic microradiographic study. Am J Orthod 68(1):4254. https://doi.org/10.1016/0002-9416(75)90158-x

14. Epker BN, Frost HM (1965) The direction of transverse drift of actively forming osteons in human rib cortex. J Bone Joint Surg Am 47:1211-1215

15. Timms DJ, Vero D (1981) The relationship of rapid maxillary expansion to surgery with special reference to midpalatal synostosis. Br J Oral Surg 19(3):180-196. https://doi.org/10.1016/0007$117 \mathrm{x}(81) 90003-2$

16. Alpern MC, Yurosko JJ (1987) Rapid palatal expansion in adults with and without surgery. Angle Orthod 57(3):245-263. https://doi. org/10.1043/0003-3219(1987)057<0245:RPEIA >2.0.CO;2

17. Angelieri F, Cevidanes LH, Franchi L, Gonçalves JR, Benavides E, McNamara JA Jr (2013) Midpalatal suture maturation: classification method for individual assessment before rapid maxillary expansion. Am J Orthod Dentofac Orthop 144(5):759-769

18. Koudstaal MJ, Poort LJ, van der Wal KG, Wolvius EB, PrahlAndersen B, Schulten AJ (2005) Surgically assisted rapid maxillary expansion (SARME): a review of the literature. Int J Oral Maxillofac Surg 34(7):709-714. https://doi.org/10.1016/j.ijom. 2005.04.025

19. Möhlhenrich SC, Modabber A, Kniha K, Peters F, Steiner T, Hölzle F, Fritz U, Raith S (2017) Simulation of three surgical techniques combined with two different bone-borne forces for surgically assisted rapid palatal expansion of the maxillofacial complex: a finite element analysis. Int J Oral Maxillofac Surg 46(10):13061314. https://doi.org/10.1016/j.ijom.2017.05.015

20. Möhlhenrich SC, Ernst K, Peters F, Kniha K, Chhatwani S, Prescher A, Danesh G, Hölzle F, Modabber A (2020) Immediate dental and skeletal influence of distractor position on surgically assisted rapid palatal expansion with or without pterygomaxillary disjunction. Int J Oral Maxillofac Surg. 50:649-656. https://doi. org/10.1016/j.ijom.2020.10.003

21. Hamedi Sangsari A, Sadr-Eshkevari P, Al-Dam A, Friedrich RE, Freymiller E, Rashad A (2016) Surgically assisted rapid palatomaxillary expansion with or without pterygomaxillary disjunction: a systematic review and meta-analysis. J Oral Maxillofac Surg 74(2):338-348. https://doi.org/10.1016/j.joms. 2015.06.161

22. Möhlhenrich SC, Heeg J, Raith S, Kniha K, Hölzle F, Wolf M, Fritz U, Modabber A (2020) Effect of the pterygomaxillary disjunction on surgically assisted rapid palatal expansion in context of orthodontic treatment. Oral Surg Oral Med Oral Pathol Oral Radiol 130(3):241-251. https://doi.org/10.1016/j.oooo.2020.03.048

23. Huizinga MP, Meulstee JW, Dijkstra PU, Schepers RH, Jansma J (2018) Bone-borne surgically assisted rapid maxillary expansion: a retrospective three-dimensional evaluation of the asymmetry in expansion. J Craniomaxillofac Surg 46(8):1329-1335. https://doi.org/ 10.1016/j.jcms.2018.05.021

24. Koudstaal MJ, Smeets JB, Kleinrensink GJ, Schulten AJ, van der Wal KG (2009) Relapse and stability of surgically assisted rapid maxillary expansion: an anatomic biomechanical study. J Oral Maxillofac Surg 67(1):10-14. https://doi.org/10.1016/j.joms.2007. 11.026
25. Elkenawy I, Fijany L, Colak O, Paredes NA, Gargoum A, Abedini S, Cantarella D, Dominguez-Mompell R, Sfogliano L, Moon W (2020) An assessment of the magnitude, parallelism, and asymmetry of micro-implant-assisted rapid maxillary expansion in nongrowing patients. Progress in Orthodontics 21(1):42. https://doi. org/10.1186/s40510-020-00342-4

26. Ramieri GA, Spada MC, Austa M, Bianchi SD, Berrone S (2005) Transverse maxillary distraction with a bone-anchored appliance: dento-periodontal effects and clinical and radiological results. Int $\mathbf{J}$ Oral Maxillofac Surg 34(4):357-363. https://doi.org/10.1016/j. ijom.2004.10.011

27. Verlinden CR, Gooris PG, Becking AG (2011) Complications in transpalatal distraction osteogenesis: a retrospective clinical study. J Oral Maxillofac Surg 69(3):899-905. https://doi.org/10.1016/j. joms.2010.11.026

28. Bonitz L, Mueller C (2013) Optimization in model-based simulations of surgical procedures - surgically assisted rapid maxillary expansion. Paper presented at the 10. Weimarer Optimierungsund Stochastiktage, 21.-22.11.2013

29. Bonitz L, Weihe S, Franz E-P, Baumann A, Hassfeld S (2009) Minimal invasive surgery for maxillary transversal distraction osteogenesis with piezo-surgery device based on a 3D finite element analysis. In, Berlin, Heidelberg. World Congress on Medical Physics and Biomedical Engineering, September 7 - 12, 2009, Munich, Germany. Springer Berlin Heidelberg, pp 106-109

30. Lines PA (1975) Adult rapid maxillary expansion with corticotomy. Am J Orthod 67(1):44-56. https://doi.org/10.1016/0002-9416(75) 90128-1

31. Andrews L (2001) Syllabus of the Andrews orthodontic philosophy. Syllabus of the Andrews orthodontic philosophy

32. Ward JH Jr (1963) Hierarchical grouping to optimize an objective function. Journal of the American statistical association 58(301): 236-244

33. Fons-Badal C, Alonso Pérez-Barquero J, Martínez-Martínez N, Faus-López J, Fons-Font A, Agustín-Panadero R (2020) A novel, fully digital approach to quantifying volume gain after soft tissue graft surgery. A pilot study. J Clin Periodontol 47(5):614-620

34. Matta R-E, Bergauer B, Adler W, Wichmann M, Nickenig H-J (2017) The impact of the fabrication method on the threedimensional accuracy of an implant surgery template. Journal of Cranio-Maxillofacial Surgery 45(6):804-808

35. Nada RM, Maal TJ, Breuning KH, Berge SJ, Mostafa YA, Kuijpers-Jagtman AM (2011) Accuracy and reproducibility of voxel based superimposition of cone beam computed tomography models on the anterior cranial base and the zygomatic arches. PLoS One 6(2):e16520. https://doi.org/10.1371/journal.pone. 0016520

36. Seeberger R, Kater W, Davids R, Thiele OC (2010) Long term effects of surgically assisted rapid maxillary expansion without performing osteotomy of the pterygoid plates. J Craniomaxillofac Surg 38(3):175-178. https://doi.org/10.1016/j.jcms.2009.07.003

37. Möhlhenrich SC, Modabber A, Kamal M, Fritz U, Prescher A, Hölzle F (2016) Three-dimensional effects of pterygomaxillary disconnection during surgically assisted rapid palatal expansion: a cadaveric study. Oral Surg Oral Med Oral Pathol Oral Radiol 121(6):602-608. https://doi.org/10.1016/j.oooo.2015.12.013

38. Matteini C, Mommaerts MY (2001) Posterior transpalatal distraction with pterygoid disjunction: a short-term model study. Am J Orthod Dentofacial Orthop 120(5):498-502. https://doi.org/10. 1067/mod.2001.118401

39. Pinto PX, Mommaerts MY, Wreakes G, Jacobs WV (2001) Immediate postexpansion changes following the use of the transpalatal distractor. J Oral Maxillofac Surg 59(9):994-1000

40. Gunbay T, Akay MC, Gunbay S, Aras A, Koyuncu BO, Sezer B (2008) Transpalatal distraction using bone-borne distractor: clinical observations and dental and skeletal changes. J Oral Maxillofac 
Surg 66(12):2503-2514. https://doi.org/10.1016/j.joms.2008.06. 105

41. Chung CH, Goldman AM (2003) Dental tipping and rotation immediately after surgically assisted rapid palatal expansion. The European Journal of Orthodontics 25(4):353-358

42. Kober C, Kannenberg S, Frank B, Al-Hakim G, Parvin A, Landes C, Sader R (2011) Computer-assisted pre- and postoperative evaluation of surgically assisted rapid maxillary expansion. Int $\mathbf{J}$ Comput Dent 14(3):233-241

Publisher's note Springer Nature remains neutral with regard to jurisdictional claims in published maps and institutional affiliations. 